\title{
3D Cadaster of Irregular Settlements in Brazil-Case Study of Belo Horizonte City
}

\author{
Plinio Temba
}

Department of Cartography, Geosciences Institute, Federal University of Minas Gerais, Belo Horizonte 31270-901, MG, Brazil

\begin{abstract}
Cadastral registration is the most important implement for land management in cities and a potential source of metropolitan solutions to urban problems because it elucidates the terrain surface situated inside an administrative-territorial unit in a well-defined emplacement-a land parcel. The paper evidences that there are three important aspects about parcels: relational database, survey of geometry and land registry. Inserting irregular settlements inside an urban development pattern is the duty of local authorities that apply the Territorial Order Plan to the slums located in the city of Belo Horizonte, Brazil. The Territorial Order is developed by the City Hall via the District Planning Secretariat, and it is approved or revised by the district itself. It concerns public areas and urban planning. The paper also presents some research results related to the cadastral aspects of spatial use above and below surface- - the 3D cadaster. The main objective of such research is to set the outlines of the development of a spatial cadastral model for irregular settlements. Finally, the paper defines the guidelines for the transition from surface cadaster into spatial cadaster.
\end{abstract}

Key words: Irregular settlements, digital cartography, 3D technical cadaster, photogrammetry.

\section{Introduction}

The informal settlement is a degraded area of public or private ownership of a city characterized by substandard housing, lack of infrastructure and without regularization. It is a characteristic of urban settlement that emerged in the early twentieth century, a consequence of the unequal economic development between the south-east versus north-northeast Brazilian's regions. The phenomenon is also propelled by the failed policies of government. Broadly, the settlements are located in areas neglected by the agents of the land market. This means devalued areas either by their location, environmental quality, levels of slope or geological problems.

It is perceived that the public and society authorities supersede that of the settlements, slums and the like arising as a defense mechanism and alternative housing for the vulnerable segments of the productive sector-particularly low-income families (according

Corresponding author: Plinio Temba, professor, research fields: photogrammetry, lasermetry, cadaster, irregular settlements. E-mail: temb@cart.igc.ufmg.br. to IBGE (Brazilian Institute for Geography and Statistics) families earning less than four minimum wages (approximately US $\$ 1,165.00$ )). On the other hand, there are observations that the occurred explosion in the housing deficit in the second half of the 1950s is a result of rural exodus due to the expansion of industrial units in the peripheries of large cities. The fact is due to the inability of government to formulate public policies compatible with the demand for housing. If the population growth of cities during the last decades led to a process of vertical integration in housing construction of the formal urban loop, settlements are however not differences except the increasing densification of buildings. This article discusses the fundamental concepts and operational weaknesses in municipal management. It describes the technical implementation of the agglomerated registry Cafezal, Belo Horizonte, MG-a relatively new problem for the illegal occupation and express characteristics/technical peculiarities of 3D cadaster in locality where exists land use planning. For fluency sake, in this text, the term "informal settlement" will 
be shortened to only settlement.

Settlements are generally associated with social problems and with rapid urbanization, as Allaway et al. [1] explain.

The central business district is still at the centre (it means urban center) and many of the nicer housings in grouped are around it, so that they have access for all the shops, cinemas, banks and offices. In addition, more nice housings take over the best land spreading outwards along a hillside or close to a beautiful part of town. On the other hand, the industry needs good transport tending to develop in wedges along the main routes to the city. People who moved to the town for work early on built houses for themselves or it was provided as social housing when the city growth was much slower. These areas tend to have most of the essential services such as clean water and sanitation and roads. But once urbanisation really took off, people arrived from the rural areas, made shacks wherever they could, often in areas prone to flooding for example or subject to other forms of pollution that no one else wanted, using whatever materials were around. They lacked paved roads and fresh water or any of the other main services, like schools and health care. The poor housing, lack of fresh water and sanitation, no electricity and unmade up roads are obvious problems. Then, social problems occur because the people arrived faster than the city could cope-and in the early days, many cities were unwilling to try too hard.

\section{The Cadaster}

Blachut et al. [2] and Erba [3] define the technical cadaster and land registration as a public record of systematic property of a court contemplated in its three fundamental aspects: the legal, economic and the geometric. The public authority is responsible for promoting and publicity to ensure the real rights, to make a fair and equitable distribution of tax burdens and to serve as an indispensable basis for projecting regional planning and public works. If the land survey favors structural elements aimed at taxation, it is called the Economic Cadaster, because it records the value of the installment from which the value of the land tax is calculated. Most of the entries currently implemented at different levels of government are still pursuing this goal, but the emergence of new evaluation methods based on construction details and location, shape and dimensions of land demanded that the databases be expanded. Most of these variables are obtained through topographical surveys, geodesic and photogrammetric or recorded in cartographic documents and alphanumeric databases that make up the Geometric Cadaster. Legislators, administrators and coaches realized that the registration has a function that goes beyond economic issues and physical and can be organized to complement the records of real estate, thus constituting the so-called Legal Cadaster.

The term land use is relatively attributed to the unit of registration on record. In legislation inspired by Roman law, the Property Law has three characters: absolute, which gives assurance to the owner to have the property in his disposal; exclusive, allowing you to use and enjoy the real estate; and perpetual, because of keeping the domain, it is not necessary to perform any legal act. However, for the property to fulfill its social function, each of these characters has its limitations (as stipulated in the law) and follows different denominations. Restrictions attack the absolute, the servitude limits the exclusivity, expropriations and the perpetuity. The relevance of the document that has an element of cartographic representation of the boundaries necessitates the need to register it in a body of land survey and the participation of a qualified professional in the process of assessment, representation and registration. The limits of the register's recorded objects are cultural ones designed for the reason that interprets a document or material facts existing in the territory. They serve as the basis for determining, according to professional criteria, where you start and end a property right, a jurisdiction, 
a political or administrative division.

Regarding the registration, there are two limits for the plots: the legal limit, which is an imaginary line that cannot be located on the land without a sign to materialize it, making their determination to require study of the titles of the plot in question plus titles of neighboring properties, and the possession limit, which is determined by the property use, as embodied by natural or anthropological entities, as shown in Fig. 1. In Brazil, most measuring tasks performed by professionals' exclusively objective measurement of lifting the existing facts, thereby determining only the limits of ownership of properties, ignore the legal causes to the corresponding effective domain. This fact eventually led to the widespread and known confounding limits and overlapping titles. This system has a weakness lack of precision caused by the subjectivity that currently exists which defines the said starting point when the plot is tied into the urban cluster. Factually, the use of this type of reference has caused major problems in territorial publicity systems of many countries, generating overlapping titles and conflicts of boundaries. In the settlements, there are more serious problems, because sometimes the lands for various reasons, are private-public, and not registered, which make it possible to ordain or over regulate work than the other locations in the city.

On the other hand, Brazilian Federal Law No. 10257 [4] establishes general guidelines for urban policy which is known as the City Statute. Moreover, it brought a distinctive look to the interpretation of urban spatial planning policy. Because municipalities give authorities, particularly the constitutional institutions of the municipality where the urban property is deemed under-utilized, and applies the compulsory use in order to guarantee a social destination for this property. This instrument will be applied to buildings built that are not fulfilling a social purpose. That is, the plots that lose their social function may be legally subjected to expropriation. Supported by the municipality status to approve the

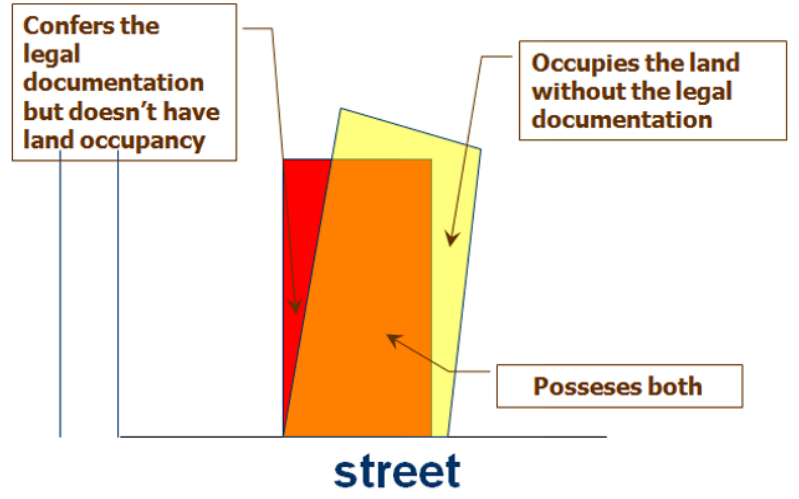

Cadastral registration - real estate cadaster

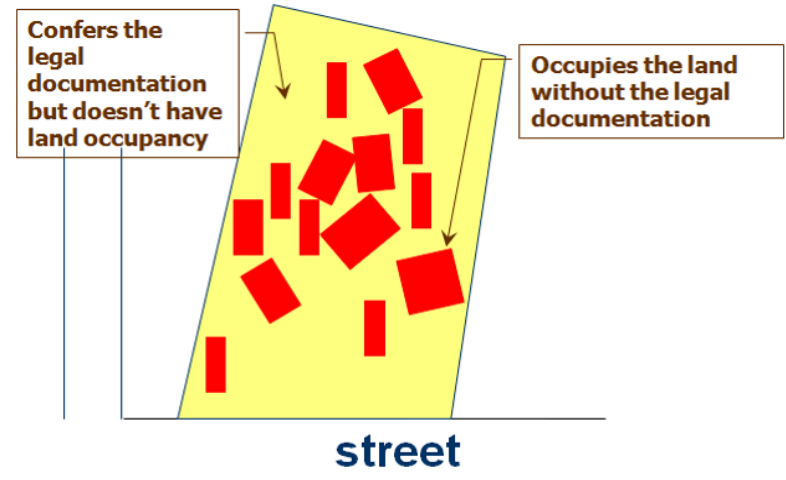

Cadastral registration - illegal occupation

Fig. 1 Technical cadaster.

Master Plan, it can establish the uses of interest for such admitted urban properties, e.g., housing, cultural centers, community centers, economic activities promoted by popular organizations and cooperatives-so as to require the owners intended use.

A major problem facing the country is irregular. The proliferation of illegal or irregular settlements, the illegal dismemberment of land and invasions of public or private areas are a reality of the model for use and occupation of urban land. Therefore, lack of control over the city's growth is common and, consequently, the informal city is not recognized. In other words, entering the real estate cadaster is usually granted only for the regular real estate, that is, those who formally received the letter of habitation or allotted in compliance with legal requirements. Only in the last 20 years, the proliferation of land tenure policies for investment agrees with the lower classes to modify the 
traditional form of settlement in cities. Housing policies, regardless of the level of government, be it federal, state or local, focus on two points:

(1) intervention in existing settlements in order to create better living conditions and raise the standard of habitability of this population;

(2) generation of new settlements for the homeless population, with priority attention being paid to the collective demands and organized.

The 2D cadaster in Brazilian cities that practice a control based cadastral adopts similar systems. There is a database Alphanumeric — organized data related to economic topics (variables that lead to determining the value of the property and tax), the geometry (such as location, shape and dimensions of the plot), the legal (which determines the relationship man-plot), social (which allows a profile of the owner or possessor).

Frédéricque et al. [5] show that RDB (relational database) where data are stored in multiple tables is interrelated by codes or identifiers. The authors propose an intelligent platform management cadaster with Oracle ${ }^{\circledR}$. These platforms provide greater speed and reliability in data maintenance, which, however, is also necessary to store information about how tables are related. They gather tables as separate plots on which physical data are recorded and services or owners of the table containing the personal data of the holder of the domain (or owner). Both tables are related by the code of the owner.

In turn, the 3D cadaster should be able to store, manipulate, query, analyze, update and view 3D cadastral objects and their associated land rights, restrictions and responsibilities. They are pointed out as crucial in understanding the definition of registration law, 3D property representation. The institutional support in the form of regulations for the acquisition of 3D data; and the tasks publicity the public and private sectors; and finally, technical assistance in registering 3D data representation, modeling and updating. The main challenges are to better understand the problems and issues associated with the incorporation of the third dimension in the registry, the specification of public policy, legal, institutional and 3D cadaster techniques, the design of 3D cadastral data model, database management 3D cadaster, and the representation of 3D cadastral model.

Belo Horizonte city hall relies on the PGE (Plano Global Específico) (Portuguese term refers to the Specific for a Global Planning) to plan and carry out structural interventions in shantytowns (also called slums, squatter settlements camps, favelas). After Ref. [6] which reviewed the city zoning, it was sanctioned. The PGE became the main legal instrument of the city hall to develop an integrated diagnosis of each settlement and, above all, the guidelines for demarcation, use and occupation of the soil. The PGE aims mainly to create an information and reference base in the context of a progressive investment policy, in an attempt to consolidate settlements and to overcome one-off and often disjointed intervention phases.

The demand for new housing for low-income families (up to 04 minimum wages, according to the IBGE) totals 7.2 million and approximately $80 \%$ of it is concentrated in urban areas, according to the Ministry of Cities. Malatsi and Finnström [7] claim that the implementation and/or the management of projects for land tenure regularization have encountered opposition and became a challenge to the authorities. Although there is no desert in Brazil, the irregular occupations are in areas undervalued by the real estate market, due to environmental restrictions and/or building constraints. These results are in increasingly numerous occupations of slopes, wetlands or mangroves as suitable housing areas. The projects for popular settlements rely on meager resources that are far from meeting the demand. The shantytowns, favelas (Fig. 2), low income housing and other settlements of the same nature in the city of Belo Horizonte occupy $4.95 \%$ of the $331 \mathrm{~km}^{2}$ of the whole 


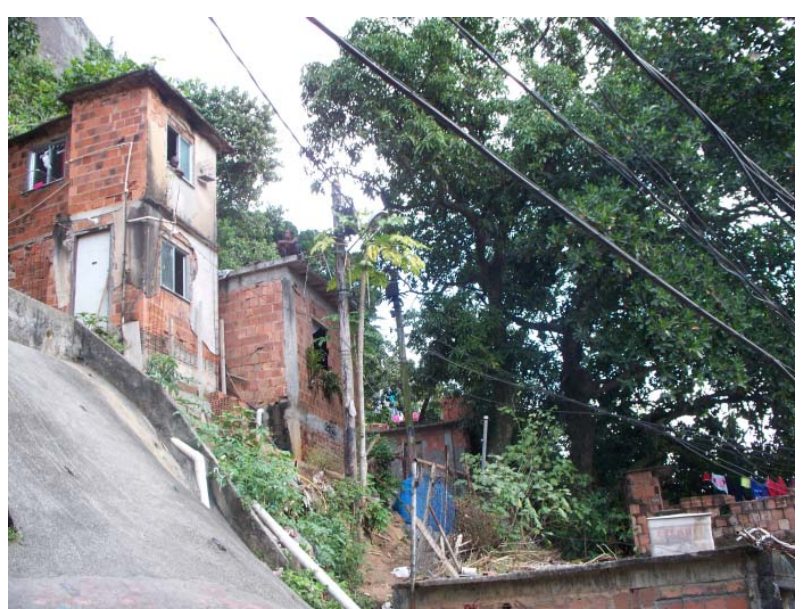

Fig. 2 Irregular settlements Rocinha (Rio de Janeiro, Brazil).

municipality territory. However, the population density in these areas is greater than in the formal city plan, concentrating $19 \%$ of the population, according to the City Hall [8].

The cartographic base files are not linked to the corresponding cadaster database. Consequently, it demands a lot of time to gather information about a particular location where one intends to carry out an organization, minimally established, to meet the planning of an intervention.

The process that precedes the cadaster is the Land Tenure Regularization Program. Municipal authorities carry out the process of regularization of settlements located in public and private area. For each situation, a procedure called Desafetação Program and expropriation should be conducted. The Expropriation Program occurs in portions of land (occupied) located in private areas where urban or community equipment facilities would be deployed and urban infrastructure projects carried out. The Desafetação Program occurred in portions of land (occupied) located in publicly owned areas. Figs. 3-7 summarize the procedures.

Research shows that 3D cadaster should be able to store, manipulate, check, analyze, update, and visualize 3D cadaster record objects and their associated land rights, restrictions and responsibilities. Another implied benefit is the opportunity to take advantage of the incipient process of settlement regulation. Since it is a new record, it is possible to experiment without compromising the organization of the $2 \mathrm{D}$ cadaster of the remainder of the city. However, it is necessary to be aware of the advantages and disadvantages of the deployment process by the City Hall, as shown in Table 1.

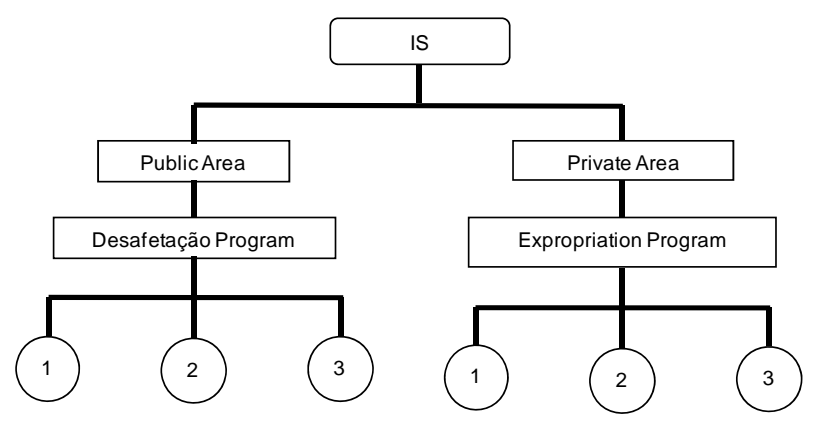

Fig. 3 Irregular settlement 3D cadastre.

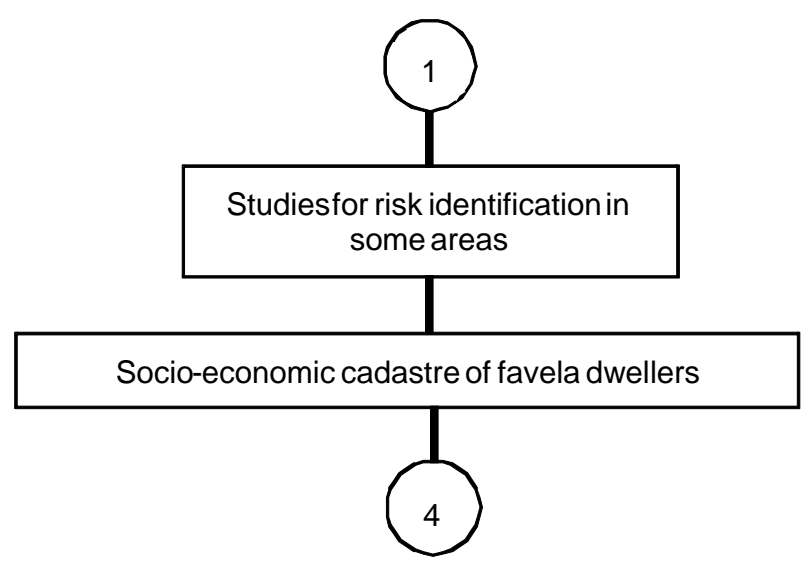

Fig. 4 Irregular settlement 3D cadastre.

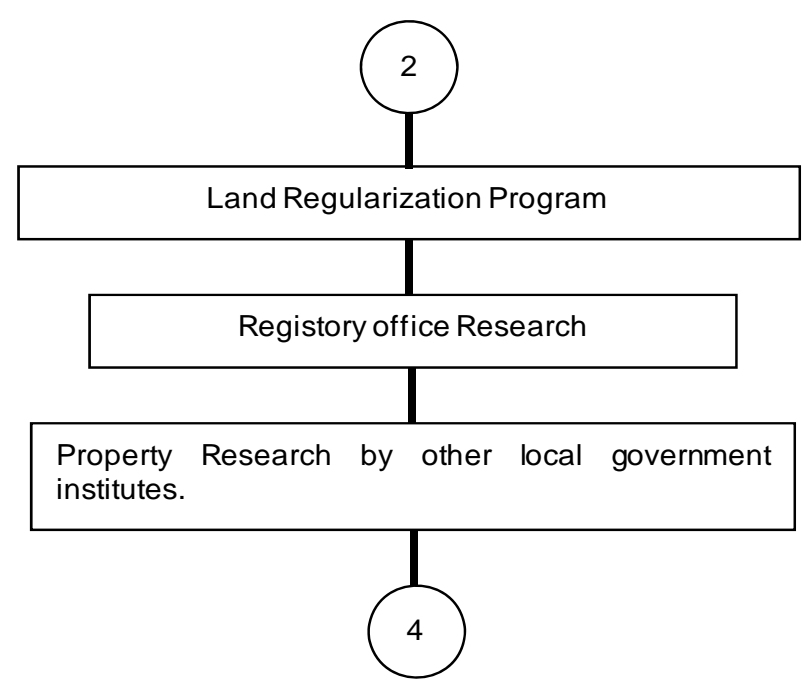

Fig. 5 Irregular settlement 3D cadastre. 


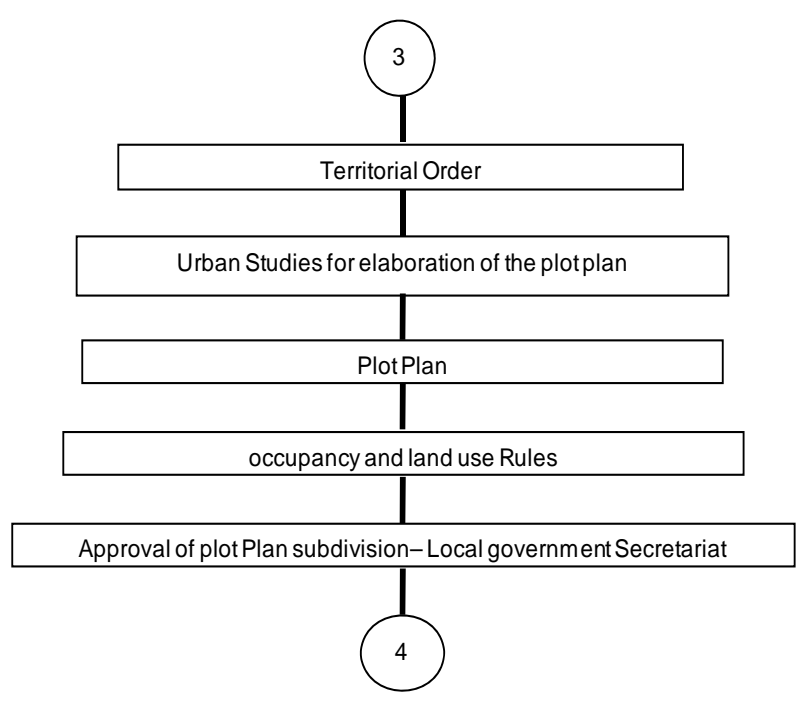

Fig. 6 Irregular settlement 3D cadastre.

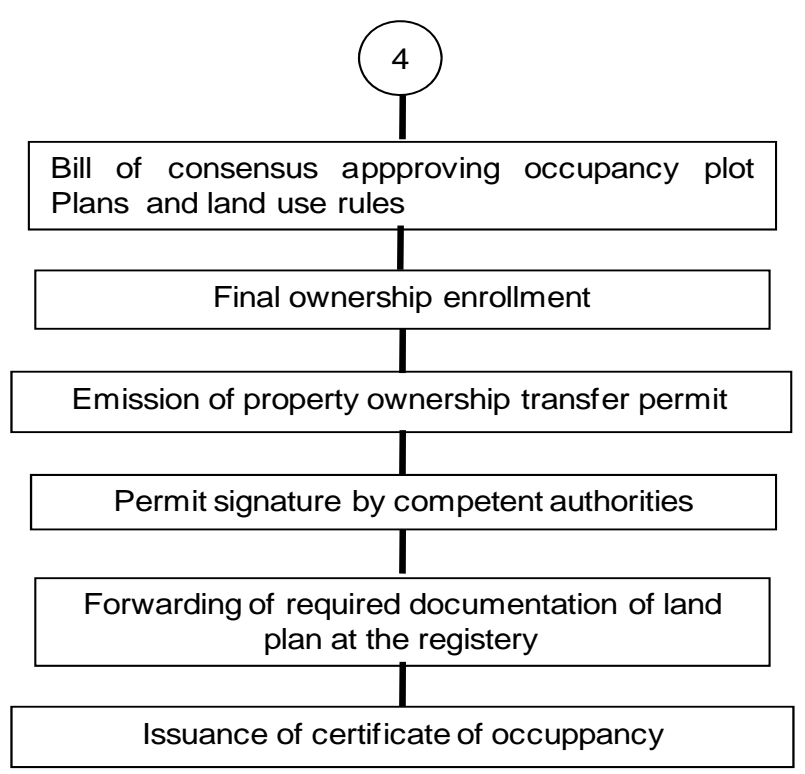

Fig. 7 Irregular settlement 3D cadastre.

Actually, there is no prospect of entering the settlements into the 3D platform, since the first challenge is to enter the buildings into the relational database. The article only points out the fact that the fledgling cadaster in these locations enables experimentation with modern concepts of cadaster, among which is the $3 \mathrm{D}$ cadaster.

\section{Materials and Methods}

The study area receives the term cluster Cafezal and has dimensions of approximately $2 \mathrm{~km}^{2}$. It is a settlement that includes the continuous extension of five villages-Cafezal Vila, Vila N. Sra. Fatima, Marcola Vila, N. Sra. Aparecida Vila, and Conceição Vila. It occupies the transition region between the two regional municipalities and East South Central. We opted for the visual classification to the detriment of mathematical operators that would make the process slower and more complex. The image selected from Fig. 8 was generated by Google Earth over the city of Belo Horizonte, Brazil.

The relational database was developed on the platform of QuantumGis ${ }^{\circledR}$ (version 1.7.0). The graphics were primitive areas. The operation took the class Boolean ordered and unordered. Fig. 9 expresses the result of the classification. The research in villages that experienced land use suffered a 3D cadaster method, alternate to record 2D practiced by local administration.

Advances in technologies used in BD (databases) and efforts to follow the current trend of object-oriented programming strengthen the research that provides the use of RDB (relational databases)

Table $13 D$ cadaster of irregular settlements: advantage vs. disadvantage.

\begin{tabular}{|l|}
\hline Advantages \\
\hline $\begin{array}{l}\text { Better understanding of the problems and issues associated } \\
\text { with the incorporation of the third dimension into the cadaster }\end{array}$ \\
\hline $\begin{array}{l}\text { Specification of public policies, legal, institutional and } \\
\text { technical aspects of 3D cadaster }\end{array}$ \\
\hline 3D registration cadaster model \\
\hline Representation of the 3D cadaster model \\
\hline System and records associated with the 3D cadaster prototype \\
\hline
\end{tabular}

Disadvantages

Vertical information is only available in the cross-sectional diagrams

Locations of cross-sections depend on decision of the licensed surveyor and are not standardized

The plans are shown on paper and cannot represent adequately the $3 \mathrm{D}$ structure

It is difficult to determine and measure the area and volume of these plans

Some rights, restrictions and responsibilities cannot be represented spatially in the plans (3D) 


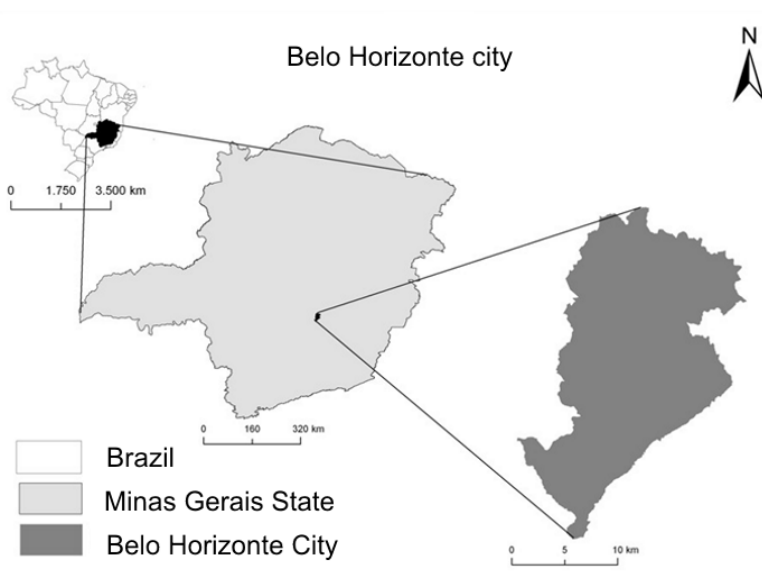

Fig. 8 Image generated by Google Earth—crowded Cafezal.

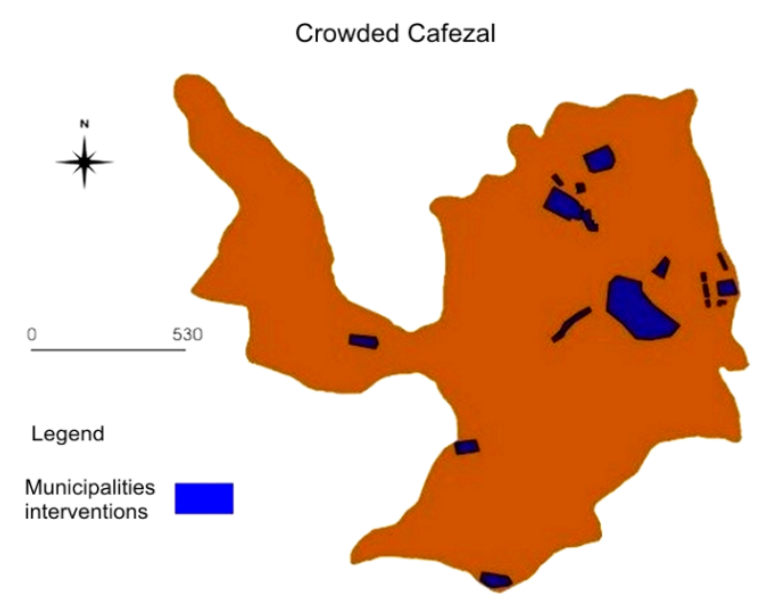

Fig. 9 Municipalities' interventions.

are indicated by Aien et al. [9] the most appropriate resources for the management of $3 \mathrm{D}$ cadaster. In the area of Geographic Information Systems, the BDOR (Database Object-Relational) is being used seeking to combine the best of both (relational and object-oriented). With the increased use of the Internet as well as increasing their access speed, the BDs for the Internet are also on the rise. Alongside these developments, the need for change in the Brazilian registration system for registering $3 \mathrm{D}$, which is currently done with the record register $2 \mathrm{D}$ plots. The storage and manipulation of 3D data $(x, y, z$ points, lines and polygons), which are possible in several databases (Oracle, Postgres, IBM, Informix), allows for many application possibilities, as well as the viability of the cadaster 3D. An example of management efficiency of the database is checked in

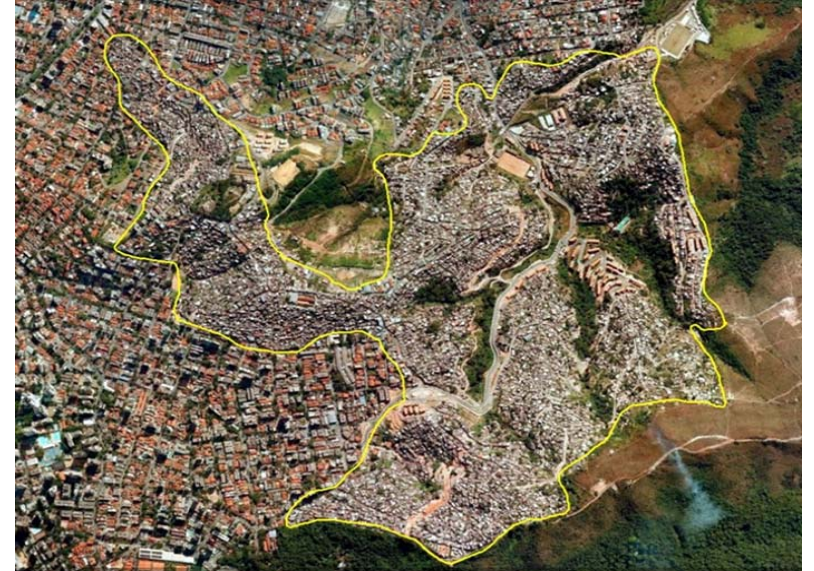

Florianópolis/SC

(http://geo.pmf.sc.gov.br/geo_fpolis/index3.php).

Local administration provides a collection of orthophotos connected to the database. Whenever the user takes the cursor over a portion in the street, the registration is indicated.

The treatment given to the cadaster resembles [10] as it combines the spatial arrangement of polygons associated with the relational database.

The registration of the plot, Fig. 10 provides for the registration of the enrollment/code, name of the sidewalk, dimensions of the front and the rear portion, supplies services (water, electricity and sewage), owner's name, Cartesian coordinates in UTM system SIRGAS and floor area of the portion of construction.

Facilities are described by Bielecka [11] for property management. With the development of applications intended to update data, verification and analysis cannot be performed in Brazilian settlements. This is because every city registers settlement data in a distinct manner. Aspects related to tabulation multiply and vary from city to city and from settlement to settlement.

It is necessary to integrate the database with the alpha-numeric geographic registration. The search engine indexed the registration of the plot recovers the 3D model of the property. The legal surveys of subdivisions approved and attended services for the settlement belonging to the database and are incorporated 

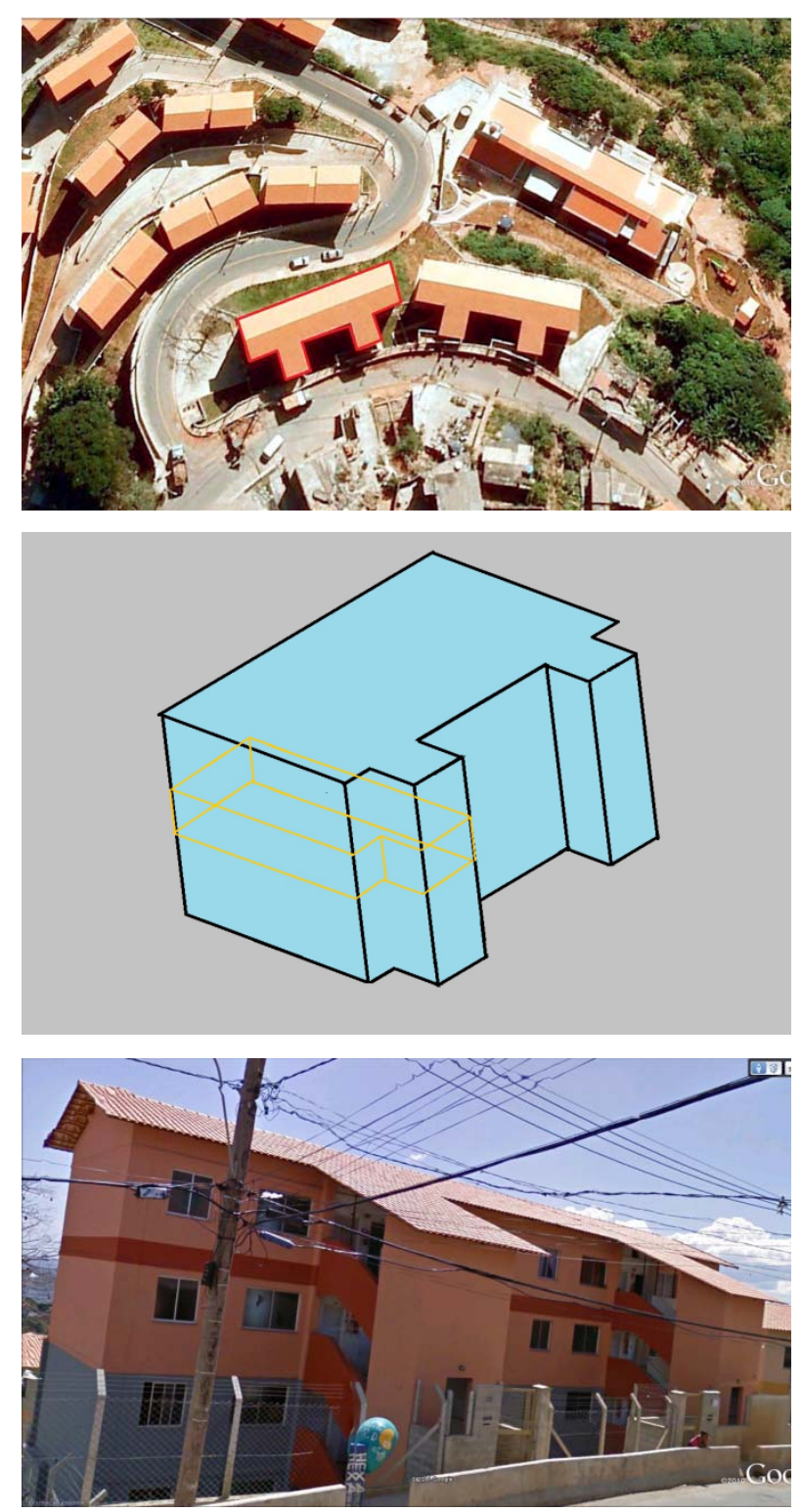

Fig. 10 On top of image reproduction with vectorization of the plot, a textured reproduction center of a 3D plot can be found beneath the property.

incorporated into a routine service. Certainly, to the public administrator, it brings about speed and efficiency in the management of 16,000 families served by the system.

\section{Reviews and Conclusions}

The case study analysis of the cluster Cafezal and the reading of current practices of 3D representation leads to some conclusions. The land use resulting from interventions in urban settlements should be careful with the registry that accompanies interventions. While the edges of the settlements are plenty of landmarks and geographic records, within them there is no clarity on the ease of access or even maintenance of integrity of installed frameworks. Traditionally, the formation of the cadastral base in the settlements is a recent practice if not ignored, so the lack of connection between the cartographic and alphanumeric information increases the risk of duplication of entries and error sum of areas of certain lots of the court, which can be lower or higher than the original area. This also makes it difficult to identify errors in cadastral data entry. The front view of the plots is not included in the registry immediately to adopt the 2D or 3D cadaster. However, it is necessary to propose building standards for all graphical plots so they can have the same expression of information. While the formal fabric of the city has a 2D cadaster, the option of adopting the 3D structure reveals a discrepancy that merits suit the surroundings with a uniform registration.

There lives in settlements $21 \%$ of the population of the Belo Horizonte city. As the reverse urban interventions of the state separated from the formal settlement to the grid, it is necessary that municipal agencies, working under the same management, share data with the same level of upgrade. If incorporated into the provision of public services follow the onus of maintenance, lack of integration between the databases arising from different city agencies can hinder and even preclude the use of some important attributes in fiscal operations. The issue is that as though tackling settlement may be precocious, it may exacerbate tax inequality since due to inefficiency of the administration, some families can enjoy the public services without sharing the costs generated by the provision of these services. Thus, families with the same economic capacity, which have properties of equal value, may receive different treatment depending on how the access to land occurs. It is therefore concluded that the technical or land survey 
records can be understood as a system of registration of spatial elements representing the urban structure, consisting of a geometric component and a descriptive that give flexibility and diversity in the provision of data to serve different functions, including urban planning.

\section{References}

[1] Allaway, R., Beckham, E., Parkinson, A., Podbury, M., and Laurie, E. 2013. "Online Resources for Teaching DP Geography.” Accessed October 12, 2014. https://drive.google.com/file/d/0BxeScMpzYGAqRFNW b0NXc2hjUlU/edit?pli=1.

[2] Blachut, T., Chrzanowski, A., and Saastamoinen, J. 1980. Urban Surveying and Mapping. Mexico: Director General of Geography in the National Territory.

[3] Erba, D. A. 2004. "Latin American Cadastres-Successes and Remaining Problems.” Accessed October 19, 2014. http://www.lincolninst.edu/pubs/883_Latin-American-Ca dastres.

[4] July 10, 2001. "Brazilian Federal Law No. 10257.” Accessed October 19, 2014. http://www.camara.gov.br/sileg/integras/463822.pdf. (in Portuguese)

[5] Frédéricque, B., Raymond, K., and Van Prooijen, K. “3D GIS as Applied to Cadastre-A Benchmark of Today's Capabilities.” Accessed September 24, 2011. http://www.gdmc.nl/3DCadastres/literature/3Dcad_2011_ 03.pdf.
[6] December 21, 2000. "Belo Horizonte Local Administration Law No. 8137.” Accessed October 12, 2014. http://www.pbh.gov.br/mapas/leiuso/lei-8137.htm. (in Portuguese)

[7] Malatsi, B., and Finnström, Å. 2013. "Reformation of Land Administration in Botswana.”Accessed October 17, 2014.

http://www.fig.net/pub/fig2013/papers/ts01a/TS01A_mal atsi_finnstrom_6589.pdf.

[8] Belo Horizonte Local Administration. 2014. "Urban Restructuring in Integrated Planning Starts up.” Accessed October 12 , 2014. http://portalpbh.pbh.gov.br/pbh/ecp/contents.do?evento=c onteudo\&idConteudo $=15985 \& \mathrm{chPlc}=15985 \& \&$ pIdPlc $=$ \&app=salanoticias. (in Portuguese)

[9] Aien, A., Rajabifard, A., Kalantari, M., and Wiliamson, I. 2011. "Aspects of 3D Cadastre-A Case Study in Victoria.” Accessed September 22, 2011. http://www.fig.net/pub/fig2011/papers/ts02g/ts02g_aien_ rajabifard_et_al_4935.pdf.

[10] Orisakwe, K. U., and Bakari, G. O. 2011. "On the Development of Cadastral Information System for Part of Kofare Government Residential Area of Jimeta-Yola in Adamawa State of Nigeria.” Accessed October 17, 2014. http://www.gdmc.nl/3DCadastres/literature/3Dcad_2011_ 03.pdf.

[11] Bielecka, E. 2011. "Data Integration within Public Property Management Systems.” Accessed October 17, 2014. http://www.fig.net/pub/fig2011/papers/ts02g/ts02g_aien_ rajabifard_et_al_4935.pdf. 